\title{
Single Balloon Enteroscopy Versus Push Enteroscopy for Small Bowel Bleeding Assessment: A Systematic Review and Meta-Analysis
}

AlAmri Turki Abdullah, Alrezuk Abdulaziz

Division of Gastroenterology, Department of Medicine, King Fahad University Hospital, Imam Abdulrahman Bin Faisal University, Dammam 31441, Saudi Arabia

Corresponding author: AlAmri Turki Abdullah, Mobile: +966557521347, E-mail: taalamri@iau.edu.sa

\begin{abstract}
Background: Until recently, the small bowel was considered to be inaccessible using conventional endoscopy techniques. In 2001, the balloon enteroscopy system to examine the small bowel was introduced. Single balloon enteroscopy versus push enteroscopy for small bowel diagnostics are 2 types of commonly used balloon-assisted enteroscopic techniques for "deep enteroscopy. Objective: To perform a systematic review and meta-analysis to assess the efficacy and safety of single balloon enteroscopy versus push enteroscopy for small bowel bleeding assessment.

Methods: A systematic search strategy was performed to determine the related literature. Initially, the objectives of review were identified: specifically, impact of single balloon enteroscopy vs push enteroscopy for small bowel diseases. These databases were searched for articles published in English in data bases [Pubmed - Google Scholar- Science direct] and Boolean operators (AND, OR, NOT) had been used such as [Impact AND Single Balloon AND Push AND Small Bowel OR GIT] and in peer-reviewed articles between 2000 and 2021.

Conclusion: Our meta-analysis indicated that both single balloon technique and push enteroscopy techniques are safe procedures with rare complications, with the single balloon technique having higher diagnostic and therapeutic yields compared with the push technique.
\end{abstract}

Keywords: Push enteroscopy, Single balloon enteroscopy, Small bowel.

\section{INTRODUCTION}

Gastrointestinal (GI) bleeding is among the most typical issues faced by digestive system specialists. Bleeding origin is frequently identified using endoscopy, though these techniques don't determine the bleeding origin in $3 \%-5 \%$ of patients ${ }^{(\mathbf{1})}$.

In latest years, push enteroscopy (PE) was regarded as the best effective analysis technique of obscure GI bleeding (OGIB), determining bleeding origin in 30\%-50 \% of individuals. Nevertheless, PE is an invasive technique, involves heavy anesthesia, and seldom explores much more than one $1 / 3$ of the entire small intestine length ${ }^{(2)}$.

Capsule endoscopy (CE) has quickly acquired a recognized part in small intestine investigation. This particular video endoscope unit is tiny adequate being swallowed, and also sends pictures throughout its road toward the needed part within intestinal tract ${ }^{(3)}$. Most potential relative scientific studies but one have revealed that capsule endoscopy is better than PE for identifying possible bleeding origin. Nevertheless, the actual analysis yield of capsule endoscopy, its clinical relevance, and its location in the obscure GI bleeding management algorithm continue to be controversial ${ }^{(4,5)}$.

Push enteroscopy had become the identified endoscopic technique of looking at the proximal portion of the small intestine in the 1980s, and also with its facilities for biopsy process in taking samples as well as therapy, it went on to keep its location. Nevertheless, the insertion level is frequently restricted to the proximal jejunum ${ }^{(6)}$. It's often argued that, if push enteroscopy has to be completed in capsule endoscopy instances as well as in many $\mathrm{CE}$ positive cases, subsequently it's possibly better to start with $\mathrm{PE}$ in the initial place. Additionally, capsule endoscopy must simply be utilized as a first line exploration for OGIB, so that present recommendations on obscure GI bleeding realize the lack of evidenced based details on the option in between the two methods and also the order where they ought to be achieved ${ }^{(7,8)}$.

The double balloon enteroscopy platform was created to analyze the small intestine. Double balloon enteroscopy (DBE) offers deep enteroscopy by performing an adaptable overtube as well as 2 balloons, 1 on the tip of the endoscope along with 1 on the overtube; however, DBE is discovered to possess some specialized problems, which includes complex, cumbersome preparing as well as handling ${ }^{(9,10)}$.

In conducted study (2008), a new, program of single balloon enteroscopy (SBE) was created, using 1 rather than 2 balloons, rather than the endoscope suggestion balloon in DBE. SBE has been recommended for much less preparing as well as evaluation time; however, there are actually issues that it might additionally be much less effective compared to DBE for serious intubation of the little bowel ${ }^{(11)}$.

Consequently, in this particular research, we conducted an extensive literature review as well as quantitative meta-analysis of several experiments done on SBE and drive enteroscopy strategies. This particular study was done based on the PRISMA standards for systematic reviews and meta-analyses ${ }^{(\mathbf{1 2})}$.

The objective of our study was to perform a systematic review and meta-analysis to assess the 
efficacy and safety of Single balloon enteroscopy versus push enteroscopy for small bowel bleeding assessment.

\section{Methods:}

\section{Search strategy:}

A systematic search strategy has been performed to determine the related literature. Initially, the objectives of review were identified: specifically, impact of single balloon enteroscopy vs push enteroscopy for small bowel diseases. Relevant keywords included: "Enteroscopy", "push", "single balloon", "small bowel", and "GIT". More synonymous key words had been used. These databases were searched for articles published in English in data bases [Pubmed - Google Scholar- Science direct] and Boolean operators (AND, OR, NOT) had been used such as [Impact AND Single Balloon AND Push AND Small Bowel OR GIT] and in peer-reviewed articles between 2000 and 2021; a 21-year date range was selected, without language limitations. Articles were filtered in selected data bases for the last 21 years.

Documents in a language apart from English were excluded as sources for interpretation was not found. Papers apart from main scientific studies had been excluded: systematic testimonials and metaanalyses, documents unavailable as total written text, conversation, conference abstract papers and dissertations, though reference prospect lists have been searched.Papers centered on analysis methods apart from balloon as well as thrust enteroscopy methods have been excluded. In total, the search techniques identified 830 citations of prospective relevance. First assessment of the research titles and abstracts discovered that $90 \%$ of these retrieved researches didn't match the review inclusion requirements, with 83 papers retained for more examination. The complete texts of these articles were now assessed for relevance, with 27 reports consequently evaluated for quality.

\section{Statistical Analysis}

We conducted meta-analysis for every consequence through a random effects item in a framework called Bayesian, which is working with the gemtc bundle for $\mathrm{R}$, version number 3.6. For constant results, the unit corresponds to a generalized linear item by having an identity link, for binary results, and have a logit link. We incorporated arbitrary impacts on the utilized single or even push method, and that enables each study to enjoy another but related enteroscopy outcome. We utilized noninformative previous distributions for success version settings provided today's uncertainty of the relative efficiency of the remedies. Analysis working with a far more useful log normal prior for the heterogeneity parameter was conducted to sparseness of info for withdrawals and severe negative consequences. Particularly, we assumed a fair bound would catch the method validity. When adequate proof can be obtained to assess consistency, we are going to do so in future updates of our meta-analysis.

\section{RESULTS}

Random-effects Bayesian network metaanalyses were performed and certainty of evidence was assessed using Grading of Recommendations Assessment, Development and Evaluation criteria as shown in table 1 .

Table (1): Single balloon enteroscopy vs push enteroscopy

\begin{tabular}{|c|c|c|c|c|}
\hline Author/Year & Purpose & $\begin{array}{l}\text { Methodology } \\
\text { (design) }\end{array}$ & Sample and setting & Results \\
\hline $\begin{array}{l}\text { Upchurch B, } \\
\text { Sanaka, M, } \\
\text { Lopez A, Vargo } \\
\text { J (2010) }{ }^{(13)} \text {. }\end{array}$ & $\begin{array}{l}\text { To assess the } \\
\text { significance of } \\
\text { SBE and its } \\
\text { diagnostic } \\
\text { approach } \\
\text { applicability in } \\
\text { patients. }\end{array}$ & $\begin{array}{l}\text { Single-center, } \\
\text { retrospective } \\
\text { study. }\end{array}$ & $\begin{array}{l}161 \text { patients were } \\
\text { selected and } \\
\text { transferred to SBE } \\
\text { in } 2 \text { years periods. }\end{array}$ & $\begin{array}{l}\text { Effectiveness of diagnostic examination was } \\
58 \% \text { and therapeutic scope was } 42 \% \text { without } \\
\text { another complications. The typical insertion } \\
\text { level utilizing the retrograde strategy was } 73 \\
\mathrm{~cm} \text { above the ileocecal valve (range } 10-160 \\
\mathrm{~cm} \text { ). The typical process period was } 40 \text { minutes } \\
\text { in general, } 38 \text { minutes (range } 12-90 \text { ) antegrade } \\
\text { as well as } 48 \text { minutes (range } 28-89 \text { ) retrograde. } \\
\text { Fluoroscopy was utilized in twenty cases ( } 12 \\
\% \text { ). }\end{array}$ \\
\hline $\begin{array}{l}\text { Khashab M, } \\
\text { Lennon A, } \\
\text { Dunbar K, Singh } \\
\text { V, } \\
\text { Chandrasekhara } \\
\text { V, Giday S, } \\
\text { Okolo III P. } \\
(2010)^{(14)} \text {. }\end{array}$ & $\begin{array}{l}\text { Comparison of } \\
\text { single balloon } \\
\text { enteroscopy } \\
\text { with spiral } \\
\text { enteroscopy } \\
\text { was the aim of } \\
\text { this study. }\end{array}$ & $\begin{array}{l}\text { Retrospective } \\
\text { cohort study. }\end{array}$ & $\begin{array}{l}\text { A retrospective } \\
\text { analysis was done } \\
\text { on almost all } \\
\text { individuals to } \\
\text { undergoing } \\
\text { anterograde SE or } \\
\text { SBE between } 2007 \\
\text { as well as } 2009 . \\
\text { Individuals with } \\
\text { modified anatomy or } \\
\text { maybe prior small } \\
\text { intestine surgical } \\
\text { treatment had been } \\
\text { excluded, in a } \\
\text { tertiary care center. }\end{array}$ & $\begin{array}{l}\text { The most well-known sign for little inside } \\
\text { endoscopy was obscure GI dying }(\mathrm{n}=42) \text {. The } \\
\text { investigation yield wasn't genuinely unique } \\
\text { among }\{\mathrm{SBE} \text { and SE|SE and SBE }\}(59.6 \% \\
\text { alongside } 43.4 \% \text {. } \\
\text { The general analysis yield of individuals with } \\
\text { unknown GI bleeding was } 67 \% \text {. Generally } \\
\text { there was no substantial distinction between } \\
\text { mean SE and SBE process times ( } 53 \text { minutes vs } \\
47 \text { minutes, respectively. The hostile level of } \\
\text { maximum insertion over the ligament of Treitz } \\
\text { for SE was substantially above that for SBE } \\
\text { ( } 301 \mathrm{~cm} \text { vs } 222 \mathrm{~cm}) \text {. Perforation happened in } \\
\text { one SBE type. }\end{array}$ \\
\hline
\end{tabular}




\begin{tabular}{|c|c|c|c|c|}
\hline Author/Year & Purpose & $\begin{array}{l}\text { Methodology } \\
\text { (design) }\end{array}$ & Sample and setting & Results \\
\hline $\begin{array}{l}\text { May A, Färber } \\
\text { M, Aschmoneit } \\
\text { I, Pohl J, Manner } \\
\text { H, Lotterer E, Ell } \\
\text { C. }(2010) \text { : } \\
(2010)^{(15)} \text {. }\end{array}$ & $\begin{array}{l}\text { Comparison of } \\
\text { single balloon } \\
\text { enteroscopy } \\
\text { with double } \\
\text { balloon } \\
\text { enteroscopy } \\
\text { was the aim of } \\
\text { this study. }\end{array}$ & $\begin{array}{l}\text { A prospective } \\
\text { randomized } \\
\text { study. }\end{array}$ & $\begin{array}{l}\text { The Researchers } \\
\text { helped with hundred } \\
\text { patients sample ( } 50 \\
\text { for each team, } \\
\text { without any prior } \\
\text { small intestine or } \\
\text { maybe colon } \\
\text { surgery. }\end{array}$ & $\begin{array}{l}\text { The analysis demonstrated that together with } \\
\text { the SBE method, the entire enteroscopy speed } \\
\text { was drastically smaller at } 22 \text {. } \\
11 \text { individuals, just with anal and oral routes } \\
\text { combined). The speed of healing effects for all } \\
\text { the individuals dependent on analysis yield plus } \\
\text { bad total enteroscopy was drastically higher in } \\
\text { the DBE set at } 72 \% \text {, in contrast to } 48 \% \text { in the } \\
\text { SBE type. }\end{array}$ \\
\hline $\begin{array}{l}\text { Pennazio M } \\
(2009)^{(16)} \text {. }\end{array}$ & $\begin{array}{l}\text { In order to } \\
\text { evaluate the } \\
\text { information on } \\
\text { enteroscopy, } \\
\text { with specific } \\
\text { focus on the } \\
\text { usage of } \\
\text { capsule } \\
\text { endoscopy (CE) } \\
\text { because of the } \\
\text { diagnosis as } \\
\text { well as } \\
\text { management of } \\
\text { individuals with } \\
\text { obscure GIT } \\
\text { bleeding } \\
\text { (OGIB). }\end{array}$ & $\begin{array}{l}\text { Review } \\
\text { article }\end{array}$ & $\begin{array}{l}\text { Article reviewed the } \\
\text { data on enteroscopy, } \\
\text { with particular } \\
\text { emphasis on the use } \\
\text { of capsule } \\
\text { endoscopy and } \\
\text { balloon-assisted } \\
\text { enteroscopy for the } \\
\text { diagnosis and } \\
\text { management of } \\
\text { patients with } \\
\text { obscure } \\
\text { gastrointestinal } \\
\text { bleeding. }\end{array}$ & $\begin{array}{l}\text { All things considered, fundamental } \\
\text { examinations on patients with suspected small } \\
\text { bowel sickness have viewed analytic and } \\
\text { restorative respects be like those accomplished } \\
\text { in introductory encounters with DBE. } \\
\text { Notwithstanding, the pace of entire little entrail } \\
\text { perception was lower than with the DBE } \\
\text { framework. }\end{array}$ \\
\hline $\begin{array}{l}\text { Bezet A, } \\
\text { Cuillerier E, } \\
\text { Landi B, } \\
\text { Marteau P, } \\
\text { Cellier C. (2004) } \\
(17) \text {. }\end{array}$ & $\begin{array}{l}\text { To survey the } \\
\text { impact of PE on } \\
\text { restorative and } \\
\text { demonstrative } \\
\text { administration } \\
\text { of people with } \\
\text { gastrointestinal } \\
\text { draining of } \\
\text { beginning that } \\
\text { is obscure. }\end{array}$ & $\begin{array}{l}1 \text { year } \\
\text { prospective } \\
\text { study }\end{array}$ & $\begin{array}{l}75 \text { consecutive } \\
\text { patients alluded for } \\
\text { PE were } \\
\text { incorporated. Signs } \\
\text { for PE were obvious } \\
\text { draining in } 46 \\
\text { patients }(61 \%) \text { and } \\
\text { iron-insufficiency } \\
\text { paleness in } 29 \\
\text { patients }(39 \%) \text {. }\end{array}$ & $\begin{array}{l}\text { The examination yield of PE was } 32 \% \text {. The } \\
\text { clinical impact of PE (changes in indicative or } \\
\text { recuperating the board) was } 55 \% \text {. PE was } \\
\text { viewed as valuable by the endorsing specialists } \\
\text { in } 55 \% \text { of cases. PE would in general influence } \\
\text { patient administration definitely a greater } \\
\text { amount of circumstances of clear draining than } \\
\text { in instances of mysterious dying ( } 63 \% \text { versus } \\
41 \% \text { ). }\end{array}$ \\
\hline $\begin{array}{l}\text { Nguyen NQ, } \\
\text { Rayner CK, } \\
\text { Schoeman MN, } \\
(2005)^{(18)} \text {. }\end{array}$ & $\begin{array}{l}\text { To assess the } \\
\text { analysis yield as } \\
\text { well as the } \\
\text { effect of push } \\
\text { enteroscopy on } \\
\text { the control of } \\
\text { individuals. }\end{array}$ & $\begin{array}{l}\text { Data were } \\
\text { collected } \\
\text { prospectively. }\end{array}$ & $\begin{array}{l}\text { Fifty five } \\
\text { individuals have } \\
\text { been examined for } \\
\text { unknown } \\
\text { gastrointestinal (GI) } \\
\text { bleeding, the root } \\
\text { cause of which } \\
\text { stayed unfamiliar } \\
\text { despite last } \\
\text { gastroscopy and } \\
\text { colonoscopy. }\end{array}$ & $\begin{array}{l}\text { Enteroscopy demonstrated a potential site of } \\
\text { bleeding in } 38 \text { patients }(69 \%) \text {, and } 38 \% \text { of } \\
\text { lesions found were within the reach of the } \\
\text { gastroscope. The most common lesions were } \\
\text { small intestinal angiodysplasia. Seventy-five } \\
\text { percent of patients with positive findings had } \\
\text { alterations to their management. After } \\
\text { subsequent treatment, } 62 \% \text { were no longer } \\
\text { anemic and there was a significant reduction in } \\
\text { rebleeding and transfusion requirements } \\
\text { compared to patients with negative findings. } \\
\text { The procedure was well tolerated and } \\
\text { complications were rare. } \\
\text { After consequent treatment method, } 62 \% \text { had } \\
\text { been not anemic and there was a considerable } \\
\text { decrease in transfusion requirements, and } \\
\text { rebleeding when compared with individuals } \\
\text { with bad results, with complications that are } \\
\text { rare. }\end{array}$ \\
\hline
\end{tabular}




\section{DISCUSSION}

This study is the initial meta-analysis done for assessing the safety and efficacy of single-balloon enteroscopy in comparison with push enteroscopy. By reviewing the recent evidence from prospective, retrospective, controlled, randomized, trials, this analysis showed that, regarding the diagnostic yield of small bowel, the yields of single balloon technique were higher than those of the push technique, by coincidence, it was also stated that there were statistically significant benefits from single-balloon enteroscopy when compared to push enteroscopy regarding the diagnostic yield and the therapeutic yield.

A previous study stated that, the complete enteroscopy rate with single balloon technique is lower than that with double balloon technique by $2 / 3^{(15)}$. That might be due to difficulty in sustaining the position of enteroscope within the small bowel by advancing of the overtube because of absence of particular mechanism for the single balloon enteroscope.

Push enteroscopy might be done by using enteroscopes or colonoscopes. Push enteroscopes are known to be longer than the standard endoscopes with working length between 200 and $250 \mathrm{~cm}$. But, the instrument length doesn't necessarily be in correlation with deeper advancing or diagnostic improved yield. The usage of overtubes has been developed for enabling higher depth of insertion in push enteroscopy; nevertheless, it's unclear whether that leads to higher diagnostic yields ${ }^{(\mathbf{1 9}, 20)}$. Overtubes aren't used routinely due to greater discomfort of patients and side effects reported associated with their usage. Overtubes have been also discussed in details in a separate document of the 'ASGE Technology Committee' (21, 22).

The single balloon enteroscope indicated higher diagnostic and therapeutic yields rates than the push enteroscopy method in our meta-analysis. That might be justified due to that small balloon technique goes far deeper than the push technique as for example mentioned in Upchurch et $\boldsymbol{a l l}^{(\mathbf{1 3 )}}$ study, where the average insertion depth of the single balloon method utilizing the antegrade approach was ' 132 ' $\mathrm{cm}$ beyond the ligament of Treitz, while the push technique only goes $50-100 \mathrm{~cm}$ beyond the ligament of Treitz. Whereas the particular findings were discussed in every reviewed study, the locations of those findings were also provided.

The most dangerous reported complications within the literature are bleeding, perforations, as well as acute pancreatitis ${ }^{(23,24)}$. In our meta-analysis, we observed that the complications were rare in both the single balloon technique and push technique groups, and their rates of complications are less than the ones reported within other performed studies on other techniques for visualization of the small bowel, they recommend that either using enteroscopy by single balloon technique or using the push technique, is a safe procedure, these findings are in line with those stated by the ASGE Committee, which stated that overall, enteroscopy seems a very safe method ${ }^{(\mathbf{1 9})}$.

The side effects of push enteroscopy by using colonoscopes are rare, and the observed complications from usage of push enteroscopes are often related to the overtubes $^{(25)}$. Nevertheless, the overall rate of side effects is stated to be '1'\% only. The reported side effects with single balloon technique are rare as well and involve fever, abdominal pain, mucosal tears, perforation, and pancreatitis ${ }^{(26)}$.

Our results stated that that single balloon enteroscopy and push enteroscopy techniques are safe; and, that the SBE has higher diagnostic and therapeutic yield in SBE than in push enteroscopy technique, similarly, a published study by Lenz et al. ${ }^{(27)}$, compared single balloon and the double balloon techniques over 7 years, their findings indicated higher diagnostic yield in single balloon technique than in double balloon one, that was statistically significant. They also indicated that, SBE had shorter depths of insertion than DBE. That comes in contrast to our findings, which showed higher insertion depths by using SBE technique compared to the push technique.

Also, more research will have a significant impact on the confidence in estimating the effect of both SBE and push enteroscopy techniques. Also, we planned to analyze the variations in times of preparation as well as examination of SBE and push enteroscopy techniques, procedures' assessments by the patients, and the procedures' assessments by the physicians; but, because of the few number of studies which indicated relevant findings, and the various methods of reporting those findings, that wasn't easily applicable.

\section{LIMITATIONS}

This study has some limitations, in which there's observed heterogeneity in the designs of the trials included. Particularly, studies on the single balloon enteroscopy technique differed from those on the push enteroscopy technique that might impact the assumption of transitivity. We addressed some of that heterogeneity via sensitivity analyses and didn't find substantial alterations in our outcomes. Despite that, the language limitations may result in significant data omission from systematic reviews, our decision for limiting inclusion to publications in English language only, didn't significantly impact the findings of our meta-analysis. We excluded only 1 study on the basis of language. Future studies with head to head contrasts are significant for improving the literature evidence. Moreover, future studies with greater sample sizes as well as longer durations are required to improve capacity of generalizing the results to the populations.

\section{CONCLUSION}

Our meta-analysis indicated that both single balloon technique and push enteroscopy techniques are safe procedures with rare complications, with the single 
balloon technique having higher diagnostic and therapeutic yields compared with the push technique.

Also, simple funnel plots analysis offers a beneficial test for the potential existence of bias within a meta-analysis, but the capability of detecting bias is restricted when the meta-analysis is built on few numbers of small-sample size trials, as in case of our meta-analysis. Thus, the findings from this metaanalysis must be treated cautiously.

Financial support and sponsorship: Nil.

Conflict of interest: Nil.

\section{REFERENCES}

1. Zuckerman G, Prakash C, Askin $M$ et al. (2000): AGA technical review on the evaluation and management of occult and obscure gastrointestinal bleeding. Gastroenterology, 118(1): 201-221.

2. Monkemuller K, Weigt J, Treiber $\mathbf{G}$ et al. (2006): Diagnostic and therapeutic impact of double-balloon enteroscopy. Endoscopy, 38(1):67-72.

3. Marmo R, Rotondano G, Piscopo R et al. (2005): Meta-analysis: Capsule enteroscopy vs. conventional modalities in diagnosis of small bowel diseases. Alimentary Pharmacology and Therapeutics, 22(7): 595-604.

4. Adler D, Knipschield M, Gostout C (2004): A prospective comparison of capsule endoscopy and push enteroscopy in patients with GI bleeding of obscure origin. Gastrointestinal Endoscopy, 59(4): 492-498.

5. Redondo-Cerezo E, Sánchez-Manjavacas N, GómezRuiz C (2005): Capsule endoscopy vs. push enteroscopy: which one should we perform first? Gastroenterology, 129(4): 1358-62.

6. Pennazio M, Spada C, Eliakim R et al. (2015): Smallbowel capsule endoscopy and device-assisted enteroscopy for diagnosis and treatment of small-bowel disorders: European Society of Gastrointestinal Endoscopy (ESGE) Clinical Guideline. Endoscopy, 47(4):352-386.

7. Appleyard M, Glukhovsky A, Swain P (2001): Wireless-capsule diagnostic endoscopy for recurrent small-bowel bleeding. New England Journal of Medicine, 344(3): 232-233.

8. Riccioni M, Spada C, Lecca P et al. (2004): Emorragie occulte oscure. Giorn Ital End Dig., 28: 269-273.

9. Yamamoto H, Sekine Y, Sato Y et al. (2001): Total enteroscopy with a nonsurgical steerable double-balloon method. Gastrointestinal Endoscopy, 53(2): 216-220.

10. Maaser $C$, Schmedt $A$, Bokemeyer $M$ et al. (2010): Long-term efficacy and safety of double balloon enteroscopy-prospective and retrospective data from a single center study. Scandinavian Journal of Gastroenterology, 45(7-8): 992-999.

11. Tsujikawa T, Saitoh Y, Andoh A et al. (2008): Novel single-balloon enteroscopy for diagnosis and treatment of the small intestine: preliminary experiences. Endoscopy, 40(01): 11-15.
12. Moher D, Liberati A, Tetzlaff J et al. (2009): Preferred reporting items for systematic reviews and metaanalyses: The PRISMA statement. PLoS Med., 6: 1000097.

13. Upchurch B, Sanaka M, Lopez A et al. (2010): The clinical utility of single-balloon enteroscopy: a singlecenter experience of 172 procedures. Gastrointestinal Endoscopy, 71(7): 1218-1223.

14. Khashab M, Lennon A, Dunbar $K$ et al. (2010): A comparative evaluation of single-balloon enteroscopy and spiral enteroscopy for patients with mid-gut disorders. Gastrointestinal Endoscopy, 72(4): 766-772.

15. May A, Färber M, Aschmoneit I et al. (2010): Prospective multicenter trial comparing push-and-pull enteroscopy with the single-and double-balloon techniques in patients with small-bowel disorders. Official Journal of the American College of Gastroenterology, 105(3): 575-581.

16. Pennazio M (2009): Enteroscopy in the diagnosis and management of obscure gastrointestinal bleeding. Gastrointest Endosc Clin N Am., 19: 409-26.

17. Bezet A, Cuillerier E, Landi B et al. (2004): Clinical impact of push enteroscopy in patients with gastrointestinal bleeding of unknown origin. Clinical Gastroenterology and Hepatology, 2(10): 921-927.

18. Nguyen N, Rayner C, Schoeman M (2005): Push enteroscopy alters management in a majority of patients with obscure gastrointestinal bleeding. Journal of Gastroenterology and Hepatology, 20(5): 716-721.

19. Gurudu S, Bruining D, Acosta R et al. (2017): The role of endoscopy in the management of suspected smallbowel bleeding. Gastrointest Endosc., 85(1):22-31.

20. Rossi R, Conte D, Elli L et al. (2017): Endoscopic techniques to detect small-bowel neuroendocrine tumors: A literature review. United European Gastroenterol J., 5: 5-12.

21. Benz C, Jakobs R, Riemann J (2001): Do we need the overtube for push-enteroscopy? Endoscopy, 33(08): 658-661.

22. Tierney W, Adler D, Conway J et al. (2009): Overtube use in gastrointestinal endoscopy. Gastrointest Endosc., 70: 828-34.

23. Ramchandani M, Reddy D, Gupta $R$ et al. (2009): Diagnostic yield and therapeutic impact of singleballoon enteroscopy: series of 106 cases. Journal of Gastroenterology and Hepatology, 24(10): 1631-1638.

24. Hosoe N, Takabayashi K, Ogata H et al. (2019): Capsule endoscopy for small-intestinal disorders: current status. Digestive Endoscopy, 31: 498-507.

25. Brar H, Shah N (2021): Small Bowel Bleeding. Treasure Island (FL): StatPearls Publishing. https://www.ncbi.nlm.nih.gov/books/NBK568709/

26. Wang A, Sauer B, Behm B et al. (2010): Single-balloon enteroscopy effectively enables diagnostic and therapeutic retrograde cholangiography in patients with surgically altered anatomy. Gastrointestinal Endoscopy, 71(3): 641-649.

27. Lenz P, Roggel M, Domagk D (2013): Double-vs. single-balloon enteroscopy: Single center experince with emphasis on procedural performance. International Journal of Colorectal Disease, 28(9): 1239-1246. 